\title{
THE MESH INFLUENCE IN FLUID FLOW
}

\section{Liviu Galateanu}

"Dunarea de Jos" University of Galati, Faculty of Naval Architecture, Galati, Domneasca Street, No. 47, 800008, Romania,

E-mail: liviu.galatanu@glo-marine.com

\section{Alin Pohilca}

"Dunarea de Jos" University of Galati, Faculty of Naval Architecture, Galati, Domneasca Street, No. 47, 800008, Romania, E-mail: alin.pohilca@glo-marine.com

\section{Matei Cosmin Baciu}

"Dunarea de Jos" University of Galati, Faculty of Naval Architecture, Galati, Domneasca Street, No. 47, 800008, Romania,

E-mail: baciumateicosmin@yahoo.ro

\section{Costel Iulian Mocanu}

"Dunarea de Jos" University of Galati, Faculty of Naval Architecture, Galati, Domneasca Street, No. 47, 800008, Romania, E-mail: costel.mocanu@ugal.ro

\begin{abstract}
The principal objective of this study is to adapt the mesh of the computational fluid dynamics to obtain a good accuracy. In the past, the experimental results were a good bench-mark for predicting ship water resistance, but due to the evolution of technology, mathematical flow patterns can be solved by applying the RANS equations. The towing test results can be applied for a low Froude number, but for a high Froude number, all phenomena that appear along the simulation aren't relevant because the scale effects cannot provide an accurate simulation of the phenomena for a real ship (scale 1:1). Hence, this study presents methods of improving the mesh quality by making comparisons with the experimental tests, and also presents the limits of the towing test results.
\end{abstract}

Keywords: mesh adapting, multihull, ship hydrodynamic resistance.

\section{INTRODUCTION}

This analysis is a continuation of the bachelor's thesis that researched the fluid flow simulation around the multi hull ship.

This study used a catamaran's shapes with characteristics presented in Table 1:

Table 1. Main particulars of the ship

\begin{tabular}{|c|c|c|}
\hline $\mathrm{L}$ & 21 & $\mathrm{~m}$ \\
\hline $\mathrm{B}$ & 6,6 & $\mathrm{~m}$ \\
\hline $\mathrm{H}$ & 2,3 & $\mathrm{~m}$ \\
\hline $\mathrm{T}$ & 1,4 & $\mathrm{~m}$ \\
\hline
\end{tabular}

\section{CONTENT}

Some major errors were obtained following the comparison between the transpo- sition of the towing tests and the numerical simulations used for the bachelor's thesis.

The transposition of the towing tests is based on ITTC standards. These standards used the wet surface of the ship and the similarity of the Froude number theory to the transposition the hydrodynamic resistance of the scaled model to the hydrodynamic resistance of the 1:1 ship (real ship).This study will show that some physical phenomena that occurred during the model testing cannot be scaled.

In this analysis we will show that the course mesh cannot generate physical phenomena on the free surface and leads to irrelevant results.

Hence, this study will look for ways to reduce these errors and assess the source of errors. 


\section{COMPARISON FOR FULL SCALE MODEL}

The first step of the transposition has used a wet surface equal to $53.9 \mathrm{~m}^{2}$, which represents the wet surface of one float of the catamaran (the second column of the table). The second step of the transposition has used a wet surface equal to $119.6 \mathrm{~m}^{2}$, which represents the wet surface of two floats of the catamaran (the first column of the Table 2.) according to ITTC rules [2].

Table 2. Comparison for full scale model

\begin{tabular}{|c|c|c|c|c|c|}
\hline \multicolumn{2}{|c|}{$\mathrm{S}=119.6 \mathrm{~m}^{2}$} & \multicolumn{2}{c|}{$\mathrm{S}=53.9 \mathrm{~m}^{2}$} & \multicolumn{2}{c|}{ CFD } \\
\hline $\mathrm{v}$ & $\mathrm{Rt}$ & $\mathrm{v}$ & $\mathrm{Rt}$ & $\mathrm{v}$ & $\mathrm{Rt}$ \\
\hline units & {$[\mathrm{kN}]$} & {$[\mathrm{m} / \mathrm{s}]$} & {$[\mathrm{kN}]$} & {$[\mathrm{m} / \mathrm{s}]$} & {$[\mathrm{kN}]$} \\
\hline 3.9 & 9.5 & 3.9 & 4.3 & 4 & 3.4 \\
\hline 5.4 & 21.5 & 5.4 & 9.6 & 5 & 6 \\
\hline 6.6 & 60.9 & 6.6 & 27 & 6 & 18 \\
\hline 7.7 & 80.1 & 7.7 & 36 & 7 & 27 \\
\hline 8.9 & 90.2 & 8.9 & 40 & 8 & 32 \\
\hline 10.1 & 92.6 & 10.1 & 41 & 9 & 33 \\
\hline 11.2 & 104 & 11.2 & 47 & 10 & 34 \\
\hline
\end{tabular}

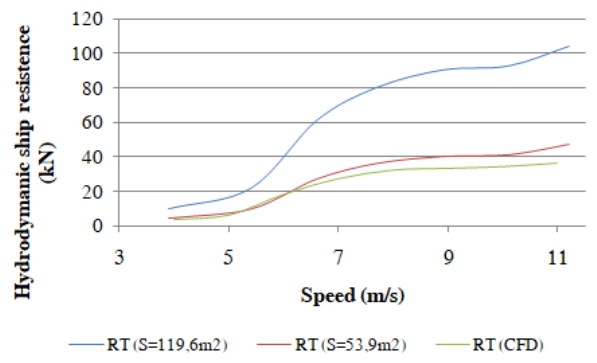

Fig. 1. Comparison chart

The blue curve from the chart (Fig.1.) is for the conversion of the results which used a wet surface equal to $119.6 \mathrm{~m}^{2}$ [3], the red curve from the chart (Fig.1.) is for the conversion of the results which used a wet surface equal to $53.9 \mathrm{~m}^{2}$ [3] and the green curve from the chart (Fig.1.) is for the numerical fluid flow simulation of the full-scale model.
As can be seen, the first step has maximum errors equal to about $20 \%$ and the second step has maximum errors equal to about $300 \%$.

Hence, this step represents the beginning of the study.

\section{THE ASSUMPTION OF THE ERRORS}

\subsection{The transposition issue}

It is complicated to find a solution to transpose the turbulent flow from the scaled model to a full scale model.

For this study it has been used a model which has $1.4 \mathrm{~m}$ in length. Hence it is complicated to compare a full scale model which has $21 \mathrm{~m}$ in length with a model which has $1.4 \mathrm{~m}$ in length because the viscosity of the water influences all flow around the model.

The turbulent kinematic energy in the wave crest presented in "Fig.2." has a high value and the steam lines in the area are not uniform.

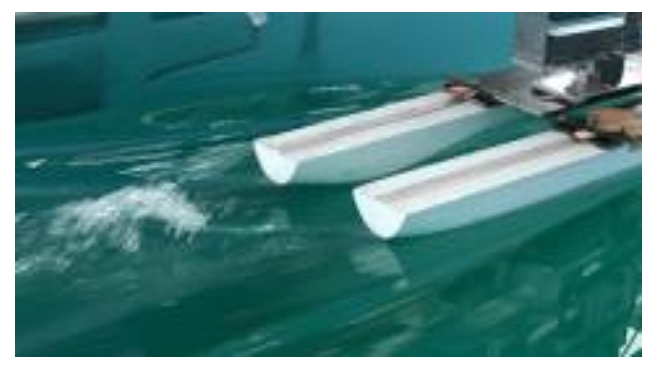

Fig. 2. Wave crest issue

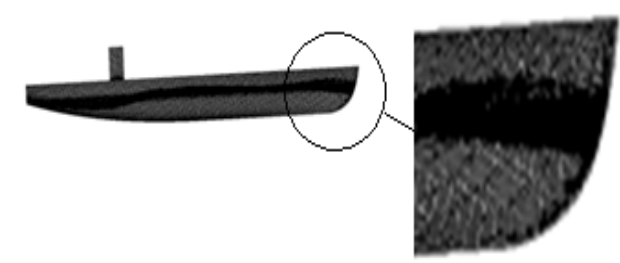

Fig. 3. First mesh issue 


\subsection{The mesh issue}

In numerical simulation, in order to capture the physical phenomena one needs to make a fine grid as to obtain all the parameters in all the points around the free surface [4]. Hence, it is necessary to have a fine surface mesh in the hull area.

In the full scale model numerical simulation, an adaptive mesh along the surface (presented in Fig.3.) has been used, but, as it will be shown, this method is not sufficient to capture the wave crest phenomena [1].

Another issue relating to the mesh is the Kelvin free surface. The Kelvin free surface represents the refinement of the mesh in the wave of the ship and is defined as a triangle in the aft and fore of the ship.

Hence, to obtain a real result of the analysis, to capture the wave crest phenomena and the energy which is consummated for generating the wave crest, one must use a fine refinement on the free surface which is presented in Fig.4 [6].

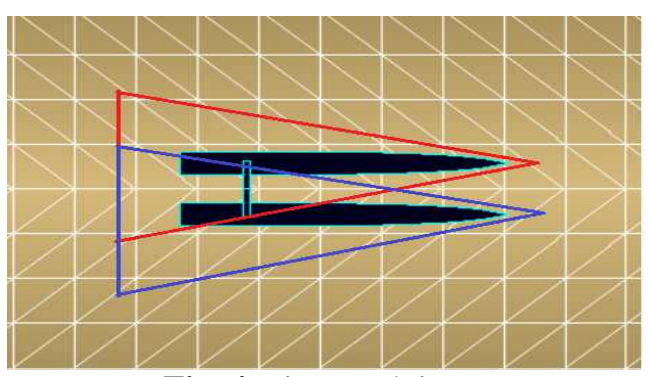

Fig. 4. First mesh issue

\section{COMPARISON BETWEEN COURSE MESH AND FINE MESH}

In order to solve the mesh issue, it has been analyzed the maximum depth of the wave through and the maximum height of the wave crest.

The mesh along the free surface has been refined based on the dimension of the wave phenomena [5].

As we can see below, the second mesh is presented in Fig.6. and Fig.8 and is much finer along the free surface than the first mesh which is presented in Fig.5 and Fig.7.

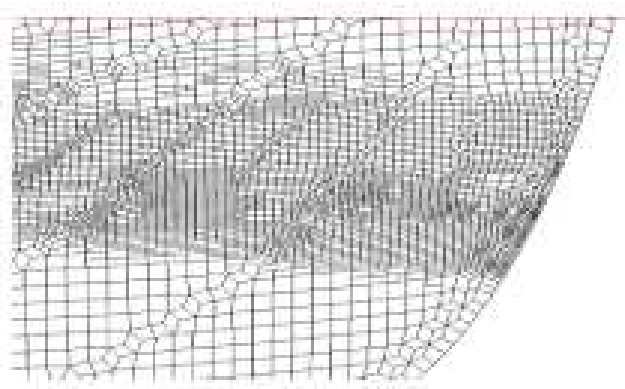

Fig. 5. First mesh - fore ship

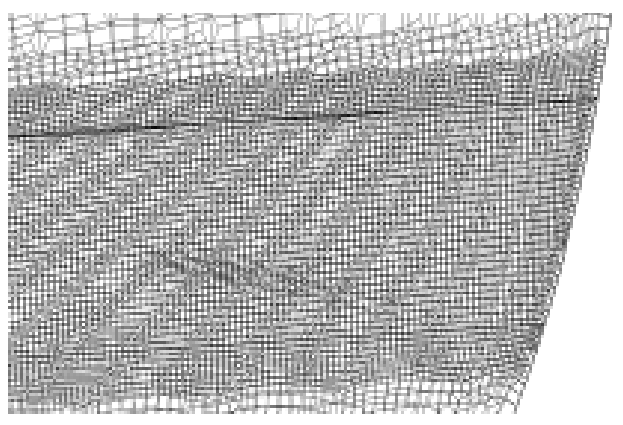

Fig. 6. Second mesh - fore ship

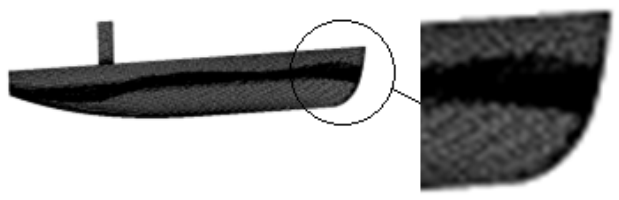

Fig. 7. First mesh - free surface

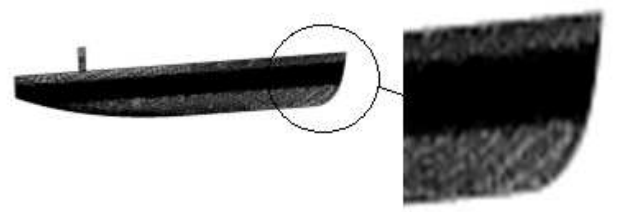

Fig. 8. Second mesh - free surface

In order to validation our assumption, these types of mesh have been applied for the scaled model and have been analyzed at 2 $\mathrm{m} / \mathrm{s}$ model ship in order to be compared to 
the experimental simulation in the towing tank.

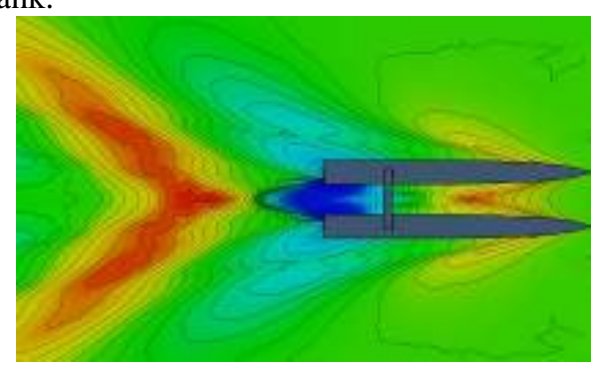

Fig. 9. First mesh - fluid flow

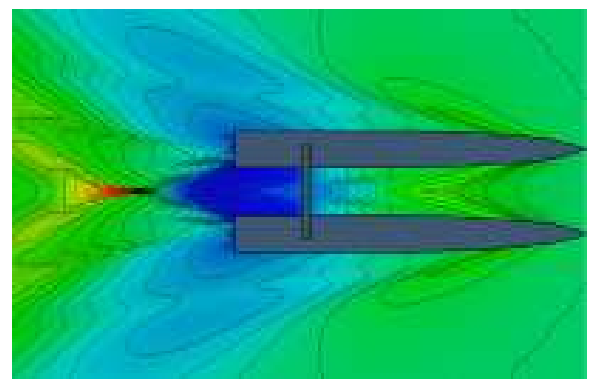

Fig. 10. Second mesh - fluid flow
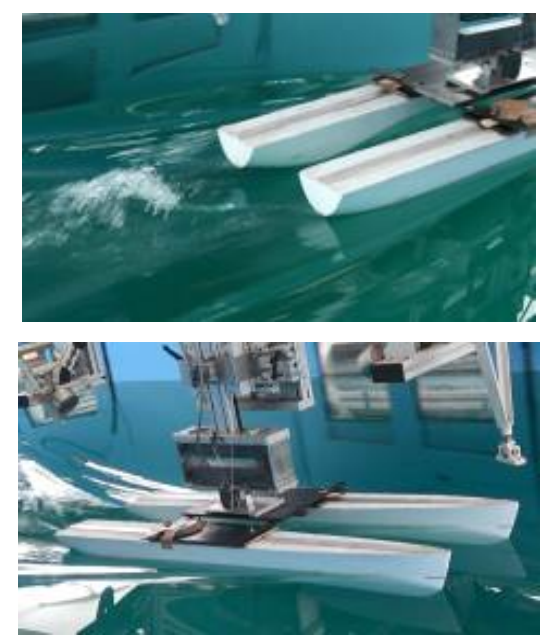

Fig. 11. Second mesh - fluid flow experiment

The representation of the phenomena along the free surface is different for these types of mesh.
In the course mesh (first mesh) case, the wave crest has extended on a large distance along the $\mathrm{Y}$ axis and the representation is not real compared with the towing tests (Fig.9.).

In the fine mesh (second mesh) case, the wave crest is the same as in the towing tests (Fig.10. and Fig.11.).

\section{COMPARISON BETWEEN FINE MESH ANALYSIS AND TOWING TEST}

Taking into account that for the second type of mesh we have obtained a good representation of the phenomena around the ship, we applied the second mesh for the entire range of speeds that were tested in the towing test.

This type of comparison is based on the computational fluid dynamics analysis of the scaled model (1:15) and the towing tank experimental probes of the scaled model (1:15).

In the below chart we can see that the maximum error is $5,4 \%$ on the high Froude number value, except the first error which is $12,3 \%$ and is the result of the low value of the hydrodynamic ship resistance (Table 3 .).

Table 3. Comparison for scaled model

\begin{tabular}{|c|c|c|c|}
\hline $\mathrm{v}$ & $\begin{array}{c}\mathrm{Rt} \\
(\mathrm{TT})\end{array}$ & $\begin{array}{c}\mathrm{Rt} \\
(\mathrm{CFD})\end{array}$ & \multirow{2}{*}{ Errors } \\
\cline { 1 - 3 }$[\mathrm{m} / \mathrm{s}]$ & {$[\mathrm{N}]$} & {$[\mathrm{N}]$} & \\
\hline 1 & 1.49 & 1.31 & $12.30 \%$ \\
\hline 1.4 & 3.26 & 3.378 & $3.60 \%$ \\
\hline 1.7 & 8.64 & 8.9 & $3.00 \%$ \\
\hline 2 & 11.37 & 11.29 & $0.60 \%$ \\
\hline 2.3 & 12.9 & 11.97 & $7.20 \%$ \\
\hline 2.6 & 13.44 & 12.78 & $4.90 \%$ \\
\hline 2.9 & 15.17 & 14.35 & $5.40 \%$ \\
\hline
\end{tabular}

The red curve from the chart (Fig.13.) is for the towing tank simulation results and the green curve from the chart (Fig.13.) is for the numerical fluid flow simulation of the scaled model. 


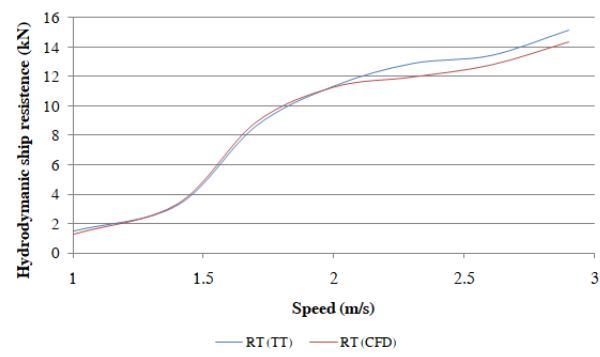

Fig. 13. Comparison chart

\section{CONCLUSIONS}

The errors which occur in last step of the study are due to the trim conditions which are presented in Table 4. Hence, it is hard to compare the towing tank test and the numerical simulations.

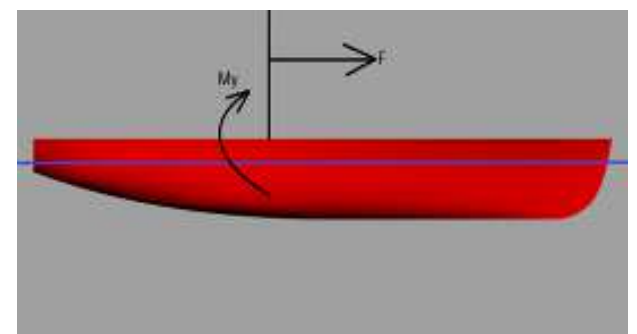

Fig. 14. Towing tank - trim conditions

Due to the model's clamping mechanism on the towing tank, the model is added a mechanical momentum that influences the hydrodynamic resistance value during the experimental analysis, as we can see in Fig.14 and Fig.15.

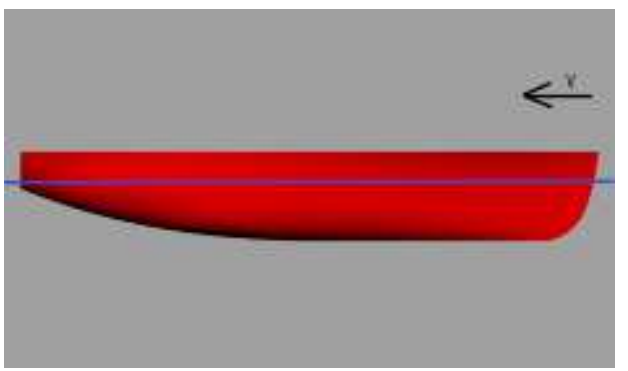

Fig. 15. CFD - trim conditions
Table 4. Trim conditions

\begin{tabular}{|c|c|c|c|}
\hline $\mathrm{v}$ & $\begin{array}{c}\mathrm{Q} \\
(\mathrm{TT})\end{array}$ & $\begin{array}{c}\mathrm{Q} \\
\text { (CFD) }\end{array}$ & $\begin{array}{c}\mathrm{Q} \\
\text { (Differences) }\end{array}$ \\
\hline$[\mathrm{m} / \mathrm{s}]$ & [grade] & [grade] & [grade] \\
\hline 1 & -0.12 & 0.02 & -0.14 \\
\hline 1.4 & 0.32 & 0.46 & -0.14 \\
\hline 1.7 & 1.33 & 2.42 & -1.09 \\
\hline 2 & 1.97 & 2.97 & -1 \\
\hline 2.3 & 1.16 & 2.77 & -1.61 \\
\hline 2.6 & 0.81 & 2.52 & -1.71 \\
\hline 2.9 & 1.45 & 2.35 & -0.9 \\
\hline
\end{tabular}

\section{Acknowledgements}

The research was supported by the Naval Architecture Faculty from "Dunarea de Jos" University of Galati, which is greatly acknowledged.

\section{REFERENCES}

[1]. ISIS-CFD Centrale Nantes / CNRS

[2]. ITTC, "CFD General, Uncertainty Analysis in CFD, Verification and Validation Methodology and Procedures", ITTC, Recommended Practice and Guidelines, 7.5-03-0101, 2008.

[3]. Olivieri, A., Pistani, F., Avanzini A., Stern, F., "Towing Tank Experiments of Resistance and Trim, Boundary Layer, Wake, and Free-Surface Flow Around a Naval Combatant INSEAN2340 Model", Iowa Institute of Hydraulic Research, The University of Iowa, IIHR report No.421, 2001.

[4]. Verseteeg, H.K., Malalasekera, W. "An Introduction to Computational Fluid Dynamics The Finite Method", Second Edition, Pearson Education Limited 1995/2007 United Kingdom, ISBN:978-0-13-127498-3

[5]. Ferziger, J.H., Peric, M., "Computational Methods for Fluid Dynamics", $3^{\text {rd }}$ Edition Springer-Verlag Berlin Heidelberg New York 2002, ISBN 3-540-42074-6

[6]. Chung, T.J., "Computational Fluid Dynamics", First Edition Cambridge University Press 2002 - United Kingdom, ISBN- 9780521594165

Paper received on July $30^{\text {th }}$, 2019 
